\title{
Low-frequency earthquakes beneath Tullu Moye volcano, Ethiopia, reveal fluid pulses from shallow magma chamber
}

\author{
Tim Greenfield ${ }^{\mathrm{a}, \mathrm{b}, *}$, Derek Keir $^{\mathrm{a}, \mathrm{c}},{ }_{\mathrm{J}}$-Michael Kendall ${ }^{\mathrm{d}}$, Atalay Ayele ${ }^{\mathrm{e}}$ \\ a School of Ocean and Earth Sciences, University of Southampton, Southampton, UK \\ ${ }^{\mathrm{b}}$ Bullard Laboratories, University of Cambridge, Cambridge, UK \\ c Dipartimento di Scienze della Terra, Università degli Studi di Firenze, Florence, Italy \\ ${ }^{\mathrm{d}}$ Department of Earth Sciences, University of Bristol, Bristol, UK \\ e Institute for Geophysics Space Science and Astronomy, Addis Ababa University, Addis Ababa, Ethiopia
}

\section{A R T I C L E I N F O}

\section{Article history:}

Received 29 January 2019

Received in revised form 12 August 2019

Accepted 16 August 2019

Available online $\mathrm{xxxx}$

Editor: M. Ishii

\section{Keywords:}

low-frequency

earthquake

Tullu Moye

volcano

fluid

Main Ethiopian Rift

\begin{abstract}
A B S T R A C T
The active magmatic processes beneath volcanoes in continental rifts is poorly understood. For example, until recently in the East African rift (EAR), the majority of the young volcanoes were thought to be inactive. More recent studies have shown that numerous volcanoes in the EAR are seismically active and deforming rapidly. However, an unambiguous sign of actively degassing magma hosted in shallow magma bodies has eluded most investigators. Here we present detailed analysis of the first low-frequency (LF) earthquake swarms to be observed in the Main Ethiopian Rift. The earthquakes locate to beneath Tullu Moye volcano and are directly related to the presence of a shallow magma body with a high fluid content. Using spectral modelling we show that the LF earthquakes appear to have low stress-drops (1-50 kPa) which we interpret in terms of low rupture velocities and high pore-fluid pressure. Careful relocation of the LF earthquakes place them approximately $4 \mathrm{~km}$ below the surface within one of two possible clusters. However, analysis of the correlation between earthquake waveforms show that each swarm contains a range of earthquake families and as such a diversity of earthquake source mechanisms. To explain these observations, we propose the seismicity is induced by $\mathrm{H}_{2} \mathrm{O} / \mathrm{CO}_{2}$ fluid pulses from the shallow magma body into a highly fractured region. Fluid pulses cause high pore fluid pressures, which also cause the low rupture velocities.
\end{abstract}

(C) 2019 Published by Elsevier B.V.

\section{Introduction}

Volcanoes are often the source of some of the most varied seismic signals observed in any geologic setting. In addition to relatively 'normal' seismicity, usually referred to as volcano-tectonic (VT) events (Roman and Cashman, 2006), there are also occurrences of earthquakes characterised by their low frequency (LF) content (McNutt, 2005). These earthquakes are usually rarer than VT events (McNutt, 2005) and signify different processes occurring beneath the volcano (Chouet and Matoza, 2013). Globally, there is a variety of observed LF events and no uniform consensus on their exact mechanism (Chouet and Matoza, 2013). This is partly because observations are often made on different volcanoes, which may or may not have the same mechanism for LF events and partly because of the complexity in modelling these events (Chouet and Matoza, 2013).

\footnotetext{
* Corresponding author.

E-mail address: tg286@cam.ac.uk (T. Greenfield).
}

Many LF earthquakes are located at shallow depths $(<1 \mathrm{~km})$ and record the movement of fluids through the shallow subsurface. Magma movement, either preceding or during an eruption is often signified by LF repeating waveforms caused by brittle failure in, or near to, the conduit. Examples include the eruption of Soufriere Hills on Montserrat (Green and Neuberg, 2006) or Mt. St. Helens (Iverson et al., 2006). These waveforms typically have extended, resonating codas which can be modelled as a tube wave resonating through the low-velocity magma conduit (Neuberg et al., 2006). Alternative models for the extended LF codas include resonating hydrothermal fractures (Chouet, 1988; Kumagai et al., 2005) or waves trapped in the surface low-velocity layer found in the unconsolidated ash and lavas on the slopes of most volcanoes (Bean et al., 2014). Most models for LF events are only applicable to shallow focus events, normally less than $1 \mathrm{~km}$ deep. At these depths, large changes in seismic velocity are common (magma/country rock, gas/country rock), and low-velocity channels act to trap waves and cause LF energy to radiate.

Deeper in the crust ( $>10 \mathrm{~km})$, LF earthquakes are associated with the movement of fluids through the crust but are not always 

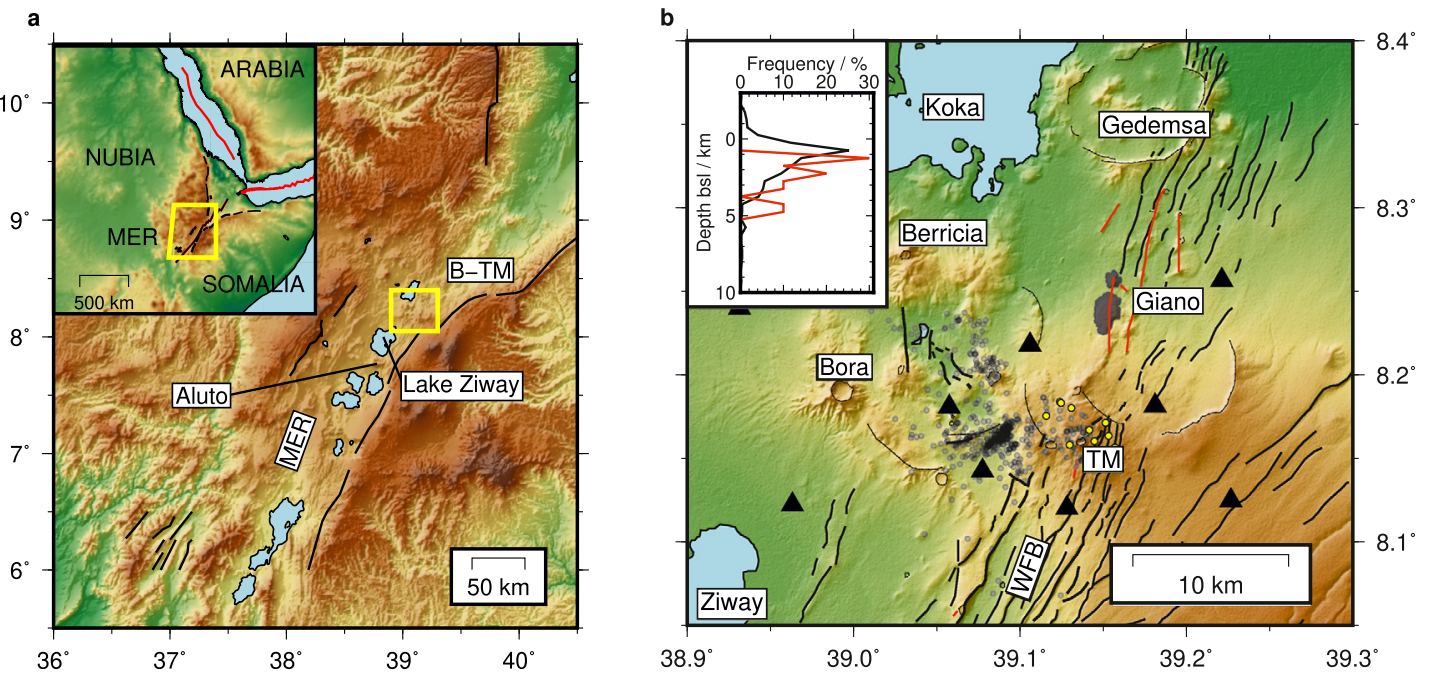

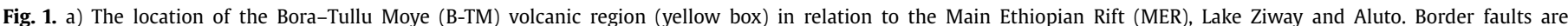

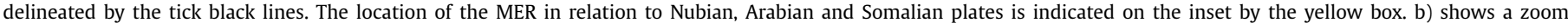

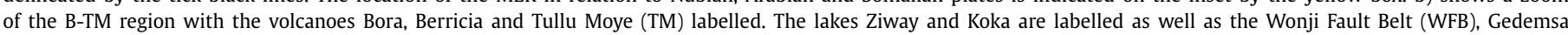

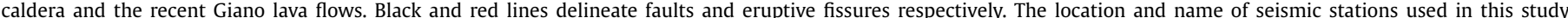

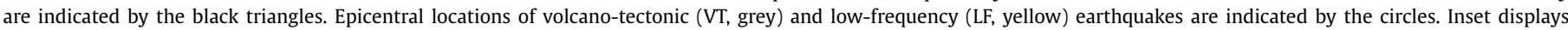

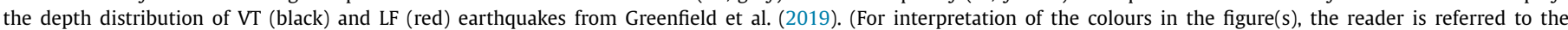
web version of this article.)

associated with imminent or ongoing eruptions (Power et al., 2004; Shapiro et al., 2017; Frank et al., 2018). To fail in a brittle manner, high temperature rocks, or magma, must have high strain rates (Tuffen et al., 2008). For example, lower crustal earthquakes beneath Askja, a volcano in central Iceland, contain lower frequencies than shallower VT events and are associated with ongoing intrusion of melt in the lower crust (Greenfield and White, 2015). In contrast to many shallow LF events, deep LF events may have identifiable P- and S-wave arrivals (i.e. Power et al., 2004). The LF nature of the waveforms is usually ascribed to slower rupture times due to higher temperatures in the source region. Importantly, LF earthquakes may reveal insights into the movement of fluids through the subsurface of a volcano and can illuminate processes which are otherwise invisible (e.g. Frank et al., 2018). We present observations of swarms of LF earthquakes located at 4-5 km depth beneath Tullu Moye (TM), a volcano located in the central part of the Main Ethiopian Rift (MER). These reveal the depth of a magma storage region beneath TM and give clues to its composition and volatile content.

\section{Geological background}

The MER accommodates rifting between the African plate (Nubia) and the Somalian plate (Fig. 1). Rifting initiated during the Miocene and was initially accommodated by motion along large border faults which form the present-day rift valley (Bonini et al., 2005; Woldegabriel et al., 1990; Wolfenden et al., 2004). Since $2 \mathrm{Ma}$, the locus of rifting has moved away from the border faults to an $\sim 20 \mathrm{~km}$ wide rift axis with Quaternary-Recent volcanoes and cones cut by small offset normal faults. The rift axis is commonly called the Wonji Fault Belt (WFB, Fig. 1) (Mohr, 1968) and is delineated by magmatic segments (Ebinger and Casey, 2001; Corti et al., 2013). Associated with the magmatic sements are a series of central volcanoes which are the manifestations of a channelised melt feeder system from the mantle to the surface.

$\mathrm{TM}$ is a central volcano located approximately $10 \mathrm{~km}$ south of the prominent caldera, Gedemsa, and centred on the WFB (Fig. 1). It is closely associated with the volcanic region of Bora-Berricia which abuts TM on its western edge. The TM region is dominated by a single, large, undated caldera with resurgent activity on it's south-west flank. The TM crater, for which the region is named, is located atop a pyroclastic cone in the centre of this more recent activity (Global Volcanism Program, 2013). A mix of both basaltic and rhyolitic products are erupted from TM, although the most recent activity is a series of obsidian domes erupted along a north trending fissure extending from TM. The most recent of these domes (Giano, Fig. 1) is dated to between 100 and 200 years ago (Gouin, 1979; Fontijn et al., 2018). A high heatflow is present across the region as indicated by an active, high-temperature hydrothermal system. Fumaroles, steam vents and altered soils are located in a number of regions across the area. The remoteness and lack of resources in Ethiopia means that TM is unmonitored and no publically available information is available on the temporal activity of the hydrothermal system.

The Bora-Tullu Moye volcanic region is one of the more active regions of the MER with $5 \mathrm{~cm}$ of uplift observed using InSAR between 2004 and 2011 (Biggs et al., 2011). Uplift was centred beneath Bora and is indicative of fluid intrusion (volatiles and/or magma) into the shallow subsurface. Earthquakes were detected in the area during a seismic network deployed between 2001 and 2003, with six located beneath the TM edifice itself (Keir et al., 2006). There was no indication of any LF events during this period, although the large spatial extent of the network meant that the small magnitude LF events, if present, were unlikely to have been detected.

The region has been the focus of a more recent and denser seismic network deployed between February 2016 - October 2017. The network consisted of up to 13 three-component broadband seismic stations recording at 50 samples-per-second and with a station spacing of between 5 and $10 \mathrm{~km}$. A total of 1200 earthquakes were detected during the length of the deployment and were analysed in the recent study of Greenfield et al. (2019). These earthquakes were predominantly VT and occurred in swarms clustered into 3 regions (Fig. 1). One cluster was located beneath the TM edifice, while the other two were not associated with any particular volcanic features. All the seismicity was located shallower than $5 \mathrm{~km}$ below-sea-level (Fig. 1). This seismicity is interpreted as being driven by hydrothermal circulation interacting with a pre-existing fault network, probably created during caldera formation. Analysis of the frequency index (amplitude ratio between two frequency 
bands) of the earthquakes revealed the presence of 13 events with significantly lower frequency content. In this study, we extend the analysis of these LF events.

\section{Methods}

\subsection{Earthquake catalogue}

We identify LF earthquakes from the catalogue of Greenfield et al. (2019) using the Frequency Index (FI). The FI (Buurman and West, 2010), defined as the logarithm of the ratio between the mean spectral amplitude within a high- $\left(6-12 \mathrm{~Hz}, A_{h}\right)$ and lowfrequency band $\left(0.6-1.2 \mathrm{~Hz}, A_{l}\right)$ (Equation (1)), is used to define whether earthquakes are LF. We correct for the effects of attenuation to estimate the source $F I$ using a simple 1D attenuation model (see Greenfield et al., 2019, for details). LF earthquakes around Tullu Moye are easily identified as those with a source FI less than zero (Fig. 2). Thirteen LF events are identified in the Greenfield et al. (2019) catalogue out of a total of 1200 (Fig. 1).

$F I=\log _{10} \frac{\overline{A_{h}}}{\overline{A_{l}}}$

Manual inspection of the seismic traces around the identified LF events reveals that the automated procedure missed many LF events. The missed events occur closely spaced in time to the previously identified events and define swarms lasting between 13 and 25 minutes (Supplementary Table 3). We manually pick the Pand S-wave arrival times for every detected event and assign each pick a quality between 0 (best) and 4 (unused). Most of the events are only observed on the closest stations and have low signalto-noise ratios. P-waves are not easily detected and many of the earthquakes only have S-wave arrival times recorded.

We identify a total of five swarms over the length of the experiment containing between 9 and 26 events (Supplementary Table 3). Swarms do not appear to be correlated with the occurrence of large teleseismic earthquakes (Supplementary Figs. 1 and 2) or during certain parts of the year. However, we note that with only 1.5 years of data it is difficult to statistically analyse any seasonal variations.

We locate LF events with more than $4 \mathrm{P}$ and $\mathrm{S}$ picks on at least 3 stations using the software NonLinLoc (Lomax et al., 2009)

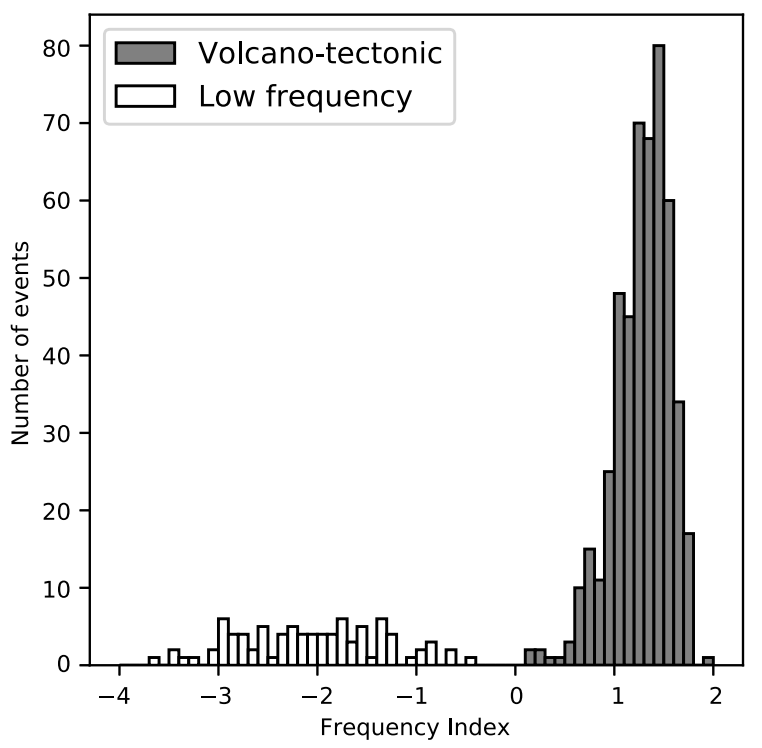

Fig. 2. Histogram of Frequency Index values for volcano-tectonic (VT) and lowfrequency (LF) events beneath Tullu Moye. Grey and white bars indicate the distributions for VT and LF events respectably. and the 1D velocity model from Greenfield et al. (2019; Supplementary Table 1). We use the equation of Font et al. (2004) to form the probability density function (pdf), as it is more stable than a L2 norm in the presence of outliers. NonLinLoc then proceeds by sampling the pdf using an oct-tree approach in which high-probability regions are further sub-divided. This reveals the maximum-likelihood location and the pdf. The full NonLinLoc run details can be found in the Supplementary Table 2 .

The low-quality nature of many of the arrival time picks and lack of P-wave arrivals results in high location errors (>15 km) and a large amount of scatter in locations (earthquakes scattered over a region more than $5 \mathrm{~km}$, Fig. 3). To improve hypocentral locations we relocate the seismicity using a double-differencing algorithm, implemented in HypoDD (Waldhauser and Ellsworth, 2000). The high degree of similarity between many of the events generates a well-constrained problem and hypocenters with significantly smaller errors ( $<2 \mathrm{~km}$, Fig. 4$)$.

To compare the waveforms generated by each earthquake, we calculate the cross-correlation coefficient between pairs of earthquakes recorded on nearby stations (Fig. 1). The waveforms are trimmed between $0.1 \mathrm{~s}$ before either the P- or S-wave (vertical or horizontal components respectably) arrival and $2.9 \mathrm{~s}$ after. In the case where the phase arrival was not manually picked, we use the theoretical arrival time calculated using a local $1 \mathrm{D}$ velocity model (Greenfield et al., 2019 and Supplementary Table 1). The waveforms are bandpass filtered between 0.5 and $3 \mathrm{~Hz}$ and then cross-correlated (Fig. 5a and b).

To generate earthquake families, in which all earthquakes correlate with each other above a defined threshold, we perform hierarchical clustering on the data. We use $D_{i j}=1-\frac{1}{N} \sum_{k=1}^{N} C_{i j k}$ as the measure of 'distance', where $C_{i j k}$ is the correlation coefficient between earthquakes $i$ and $j$ recorded on station-component, $k$, and $N$ is the total number of station-components (De Meersman et al., 2009). The results are plotted as dendrograms (Fig. 5c) where clusters of events which have inter-correlation coefficients greater than 0.75 are coloured.

\subsection{Stress drops}

We calculate the stress drops of earthquakes by modifying the methods described by Abercrombie (1995) and Edwards et al. (2010). We generate $5.2 \mathrm{~s}$ long waveform snippets around the Swave (horizontal components) arrivals for stations which record each earthquake. The waveform snippets are then detrended, tapered using a $5 \%$ cosine taper, integrated to displacement and have the instrument response removed. Each snippet is then padded with zeros to a length of 1024 samples and has its amplitude spectra calculated using the multi-taper method (Park et al., 1987; Prieto et al., 2009). We perform the same analysis on windows of data before each P-wave arrival to estimate the noise level of each observation (Fig. 5).

Spectral fitting is performed on portions of the spectra where the signal-to-noise ratio (estimated from the pre-P-wave arrival noise) is more than 3 . We fit the generated spectra to the generalised Brune $\omega^{-2}$ model (Abercrombie, 1995):

$\Omega(f)=\frac{\Omega_{0} e^{-(\pi f t / Q)}}{\left[1+\left(f / f_{c}\right)^{\gamma n}\right]^{1 / \gamma}}$,

where $\Omega_{0}$ is the long-period spectral level, $f$, the frequency, $f_{c}$, the corner-frequency, $t$, the travel time between source and receiver, $Q$, the frequency-independent quality factor, $n$, the highfrequency fall-off rate (on a log-log plot) and $\gamma$, is a constant. When $t=0, n=2$ and $\gamma=1$; (2) is the same as the model originally described by Brune (1970). An alternative model proposed by Boatwright (1980) in which $\gamma=2$ and the corner is sharper was 

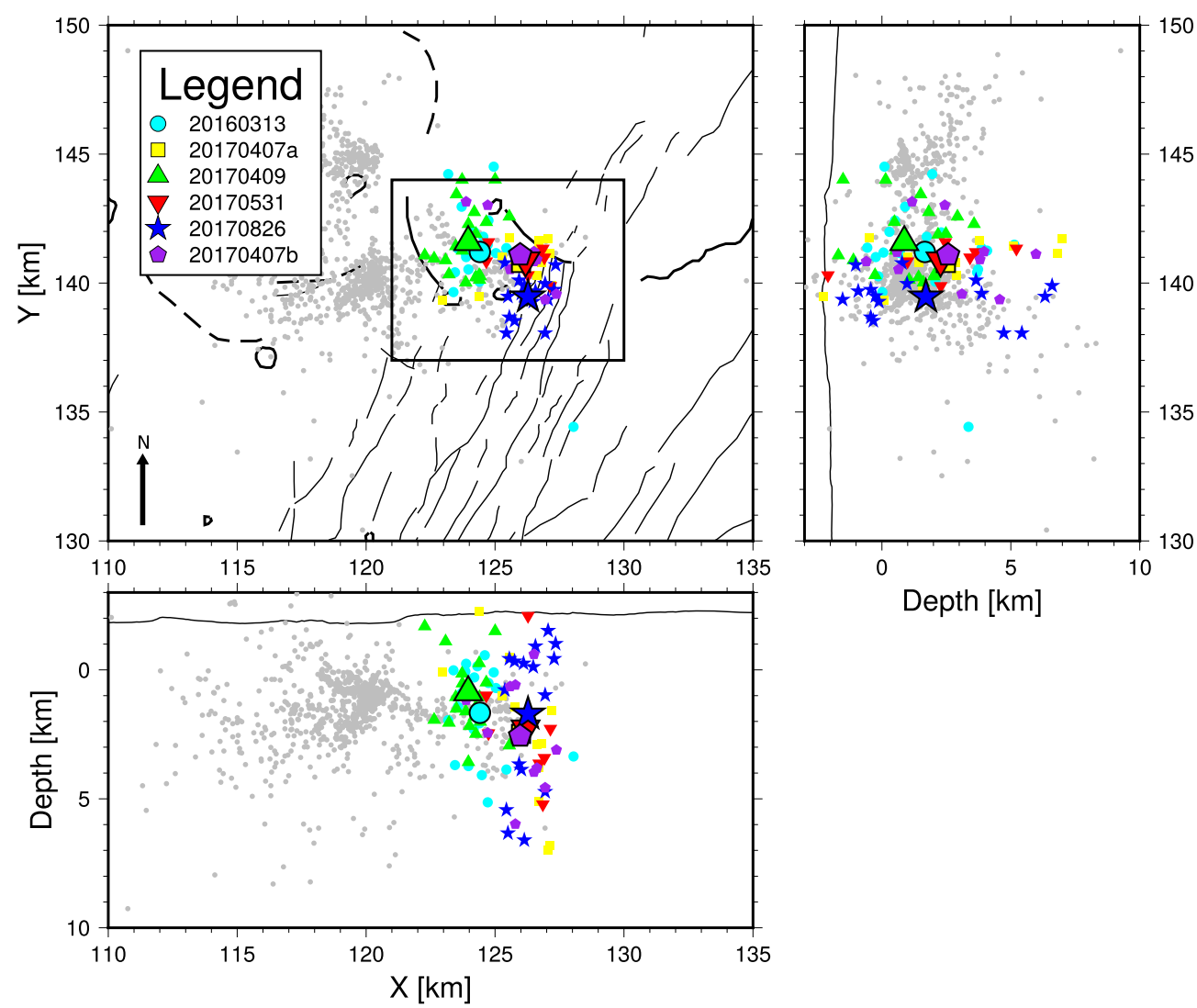

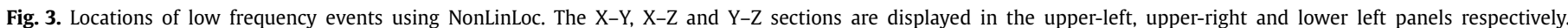

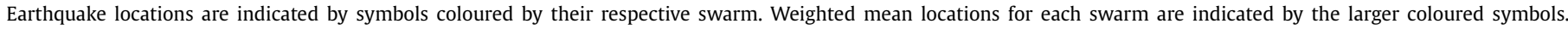

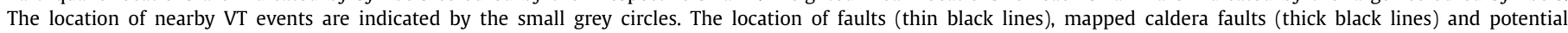
caldera faults (thick dashed lines) are delineated on the upper-left panel. The black box indicates the region plotted in Fig. 4.

found to not improve the fit to the data, so we use the original Brune (1970) model.

The Brune model contains three fitting parameters: $\Omega_{0}, Q$ and $f_{c}$. We perform spectral fitting using a grid-search over all possible $f_{c}$ values between $0.1-100 \mathrm{~Hz}$ sampled in logspace. For each value of $f_{c}$, a Nelder-Mead minimisation algorithm is then used to minimise the root-mean-square misfit between the data and model for $\Omega_{0}$ and $Q$ at each $f_{c}$ value (Fig. 6). By fitting the misfit function with a polynomial around the minima, we interpolate to find the global minimum and output the best-fitting $\Omega_{0}, Q$ and $f_{c}$. We estimate the error in $f_{c}$ by outputting the range of $f_{c}$ with misfits less than $10 \%$ greater than the global minimum.

To calculate the stress drop from the earthquake spectra we make standard assumptions. The first is that the geometry of the earthquake rupture is circular with radius, $r$, which, for these small magnitude earthquakes is likely to be the case. Given this assumption, the uniform stress drop, $\Delta \sigma$, is related to the moment, $M_{0}$, and $r$ through the analytical result from Eshelby (1957):

$\Delta \sigma=\frac{7}{16} \frac{M_{0}}{r^{3}}$.

The second assumption is that corner frequency is related to the radius through the equation (Brune, 1970; Madriaga, 1976),

$f_{c}=k \frac{V_{s}}{r}$,

where $V_{s}$ is the shear wave velocity and $k$ is a constant that relates to the spherical average of corner frequencies for a specific theoretical model. By combining (3) and (4), the stress drop can be estimated using the corner frequency and the seismic moment, both of which can be estimated from earthquake spectra. An important feature of these equations is that any errors in $k, V_{s}$ and $f_{C}$ are cubed when (3) and (4) are combined, so it is vital that accurate estimates of these parameters are made. We use shear wave velocities from a local 1D model (Greenfield et al., 2019) and, as discussed above, propagate any errors in the $f_{c}$ into the final stress drop estimates.

The constant $k$ is dependent on both the model used and the type of wave analysed. We use more recent calculations from Kaneko and Shearer (2014) rather than the commonly used Madriaga (1976) values. Kaneko and Shearer (2014) construct a model similar to the dynamic model from Madriaga (1976), but avoid stress singularities at the rupture front by including a cohesive zone in which shear strength of the fault reduces with distance. For rupture velocities $\left(V_{R}\right)$ equal to $0.9 V_{s}$, the $k$ values for P- and S-waves are respectively 19 and 24 per cent larger in the Kaneko and Shearer (2014) model than with the Madriaga (1976) model. Kaneko and Shearer (2014) also calculate $k$ for $V_{R}$ varying between $0.5 V_{s}$ and $0.9 V_{s}$, allowing us to see what effect the rupture velocity has on the calculated stress drops. Direct inversion for the source mechanisms of the earthquakes (e.g. Ominato et al., 1998); which would have given us the source time function and therefore an estimate of the rupture velocity was attempted. However, the station distribution and signal to noise ratio was not sufficient to produce stable results.

\subsection{Earthquake magnitudes}

The local magnitude $\left(M_{L}\right)$ of each event is calculated by first deconvolving the instrument response of the recorded waveforms and convolving the response of a Wood-Anderson seismograph. 

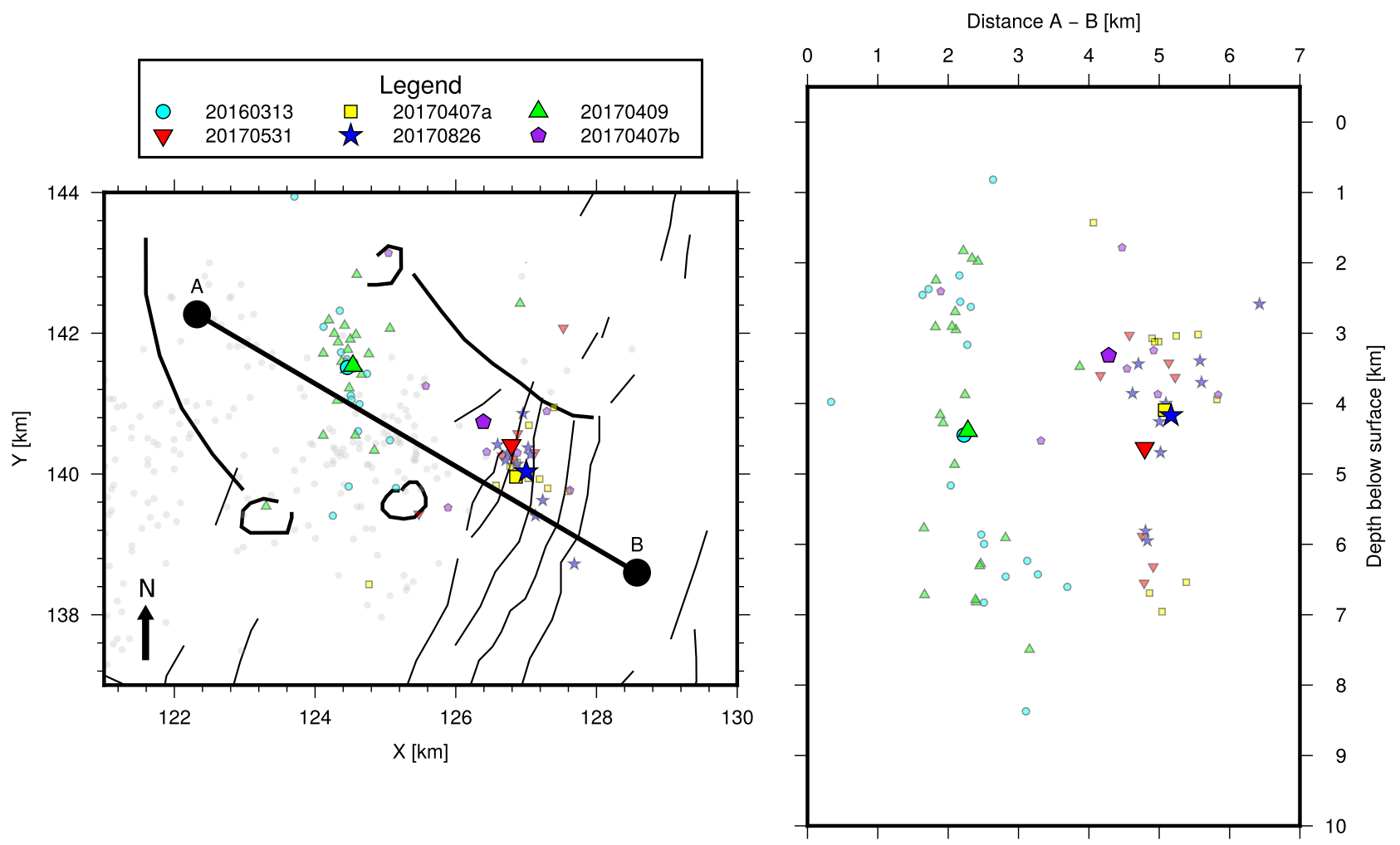

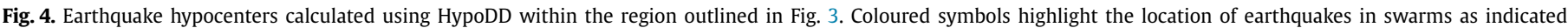

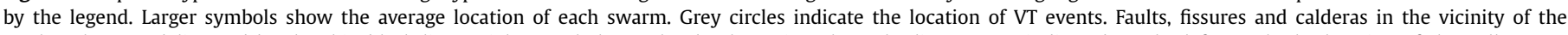

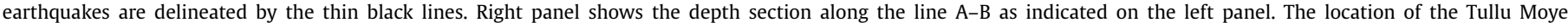
crater is near the centre of the left panel.

The maximum zero-to-peak amplitude (in $\mathrm{mm}$ ) of each event is then inserted into the $M_{L}$ equation from Keir et al. (2006 and Supplementary Information). The final value of $M_{L}$ is output as the mean $M_{L}$ using all stations with phase pick arrivals.

The seismic moment $\left(M_{0}\right)$ for both LF and VT events is calculated from,

$M_{0}=\frac{4 \pi \rho c^{3} d \Omega_{0}}{U_{\theta \phi}}$,

where $\rho$ is the density, $c$ is the wave speed, $d$ is the distance from the source and $U_{\theta \phi}$ is the mean radiation over the focal sphere ( 0.63 for S-waves) and is needed when calculating the stress drop. Despite scatter, there is a clear relationship between the logarithm of $M_{0}$ and $M_{L}$ (Fig. 7). However, the relationship is different for VT and LF events. LF events are observed to have higher moments than VT events at the same $M_{L}$. This could be because the WoodAnderson instrument response, used in the $M_{L}$ calculation, does not have sensitivity to the low frequencies in the LF events. Of note, is that the relationship between $\log _{10} M_{0}$ and $M_{L}$ has a gradient closer to 1 rather than the expected value of $2 / 3$ (Kanamori, 1977). The higher gradient for low magnitude events $\left(M_{L}<3\right)$, was previously seen in Southern California (Shearer et al., 2006). As such, we calculate the moment magnitude for the events using

$M_{w}=\log _{10} M_{0}+C$,

where $C$ is a constant. $C$ is calculated by assuming that moment magnitude calculated using the Kanamori (1977) equation and the moment magnitude as we calculate it $\left(M_{w}\right)$, is equal when both are equal to 3 . Following this, $C$ equals -10.545 . The relationship between calculated $M_{w}$ and $M_{L}$ for each earthquake is shown in Fig. 7a. The gradient between the two magnitude estimates is close to 1 , although neither the VT events or LF events have a $1: 1$ relationship. In the case of the VT events, $M_{L}$ is overestimating $M_{w}$. This could be because the large proportion of short source-receiver offsets in our experiment. Raypaths for these short offsets spend longer (as a percentage) in the highly attenuating near surface layers and as a result $M_{L}$ can, counter-intuatively, be overestimated (Butcher et al., 2017). In contrast, the $M_{L}$ of LF events is underestimating $M_{w}$. As discussed above, this is probably due to the low-sensitivity of the Wood-Anderson seismograph to low frequencies.

\section{Results}

\subsection{Earthquake properties}

The low-frequency earthquakes are clustered beneath Tullu Moye volcano (Fig. 3). Relative relocations of the well-located events (Fig. 4) indicate two locations with a high likelihood of earthquakes occurring: northwest and east of TM crater. In depth, the LF earthquakes are most likely located between 3 and $7 \mathrm{~km}$ below the surface, although the error in depth is quite large. The nearby VT earthquakes have epicentres that lie to the southwest of LF seismicity (gray circles, Fig. 4) and are not located in the same clusters as the LF events. In depth the VT and LF earthquake distribution overlap significantly (Fig. 3).

\subsection{Earthquake similarity}

Using cross-correlation coefficients (CC), the similarity between LF earthquakes can be assessed. We find that, surprisingly, earthquakes within a single swarm are not all highly correlated (defined as CC $>0.75$, Fig. 5). Instead, numerous earthquake families are observed (Fig. 8). This indicates that either earthquakes within a 


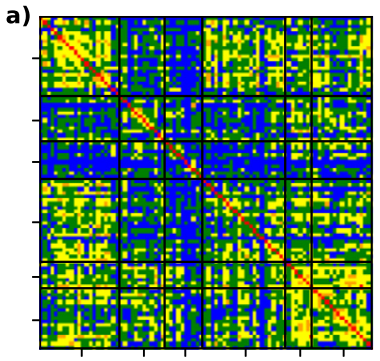

c)
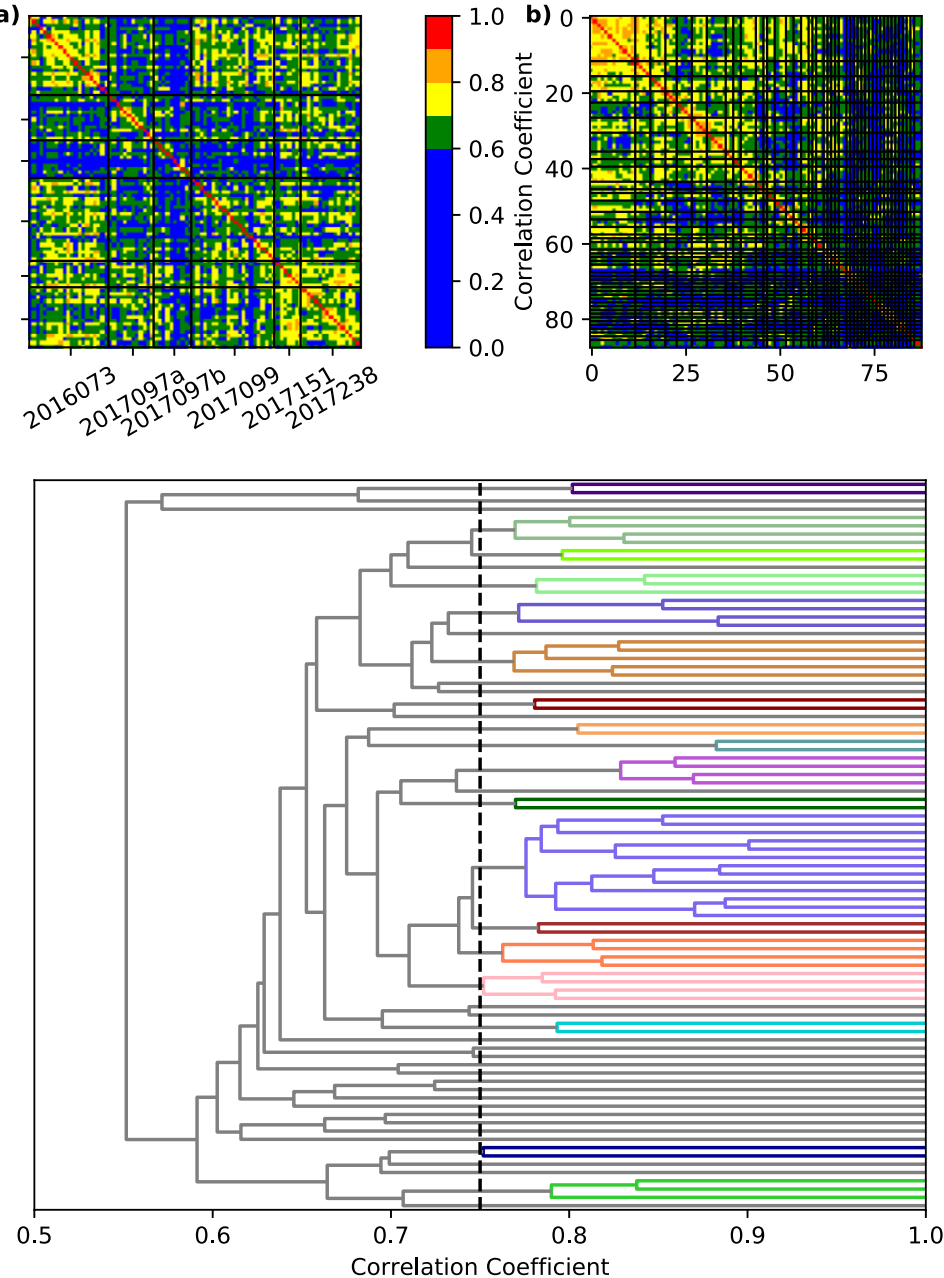

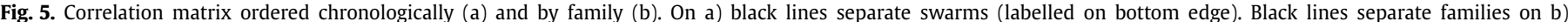

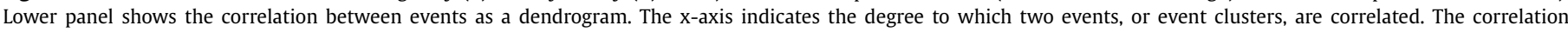
coefficient we use to define a cluster is indicated by the vertical dashed line.
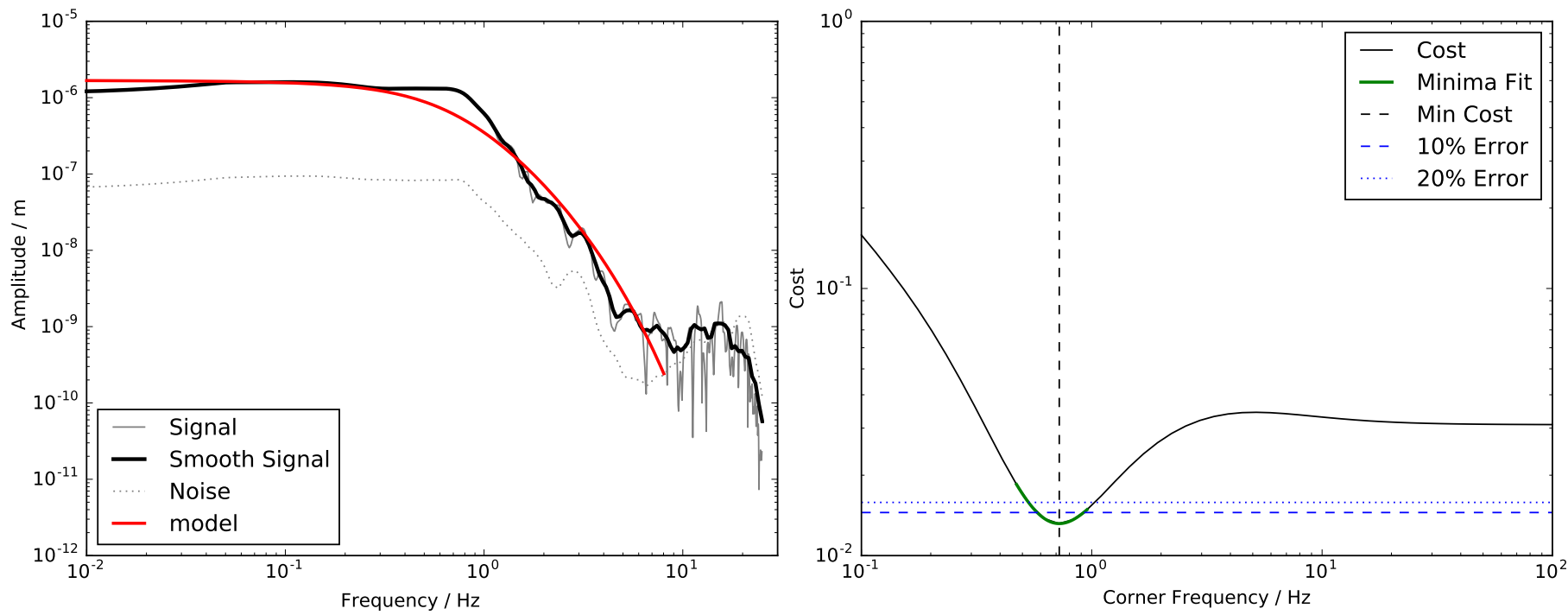

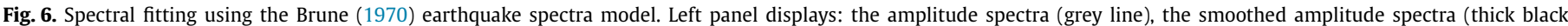

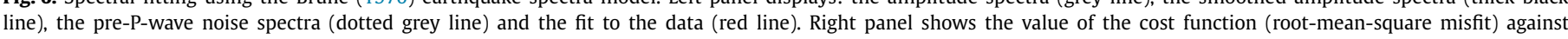

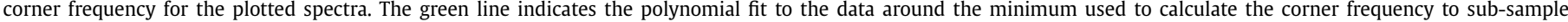
precision and estimate the error. The values of misfit corresponding to $10 \%$ and $20 \%$ error is indicated by the blue dashed and dotted lines respectively. 

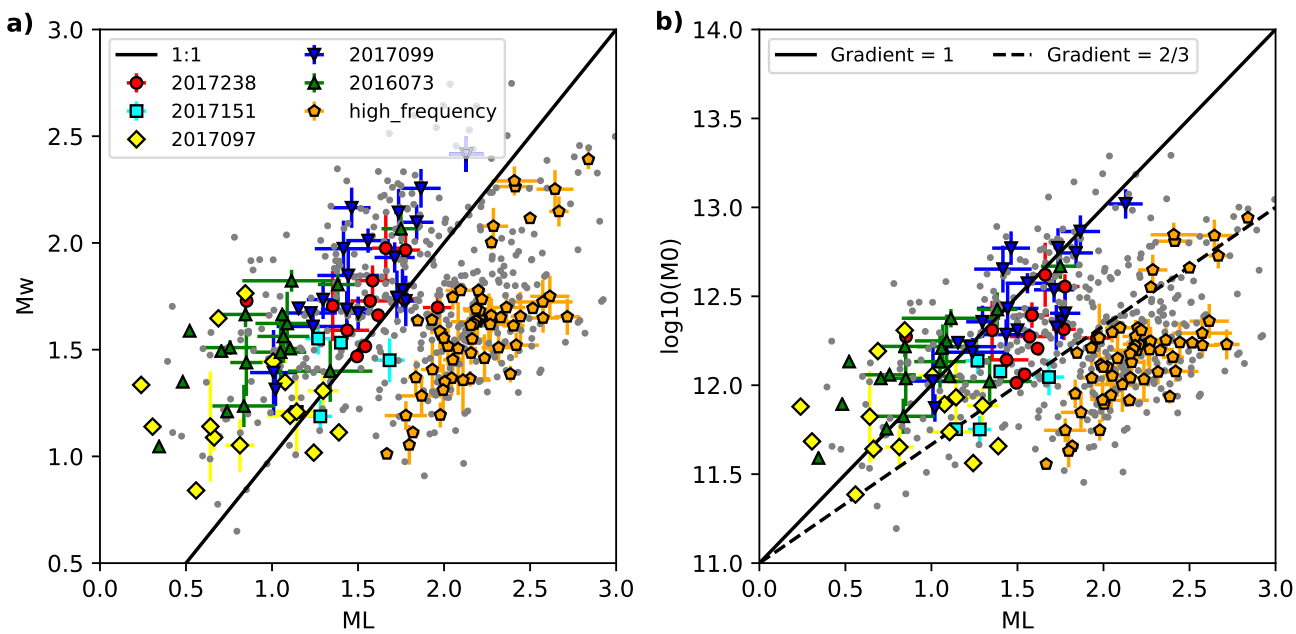

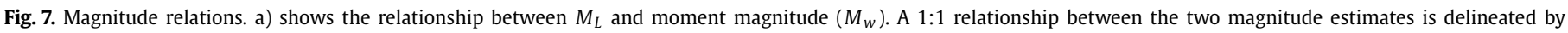

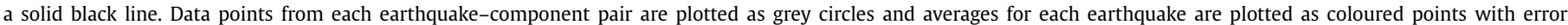

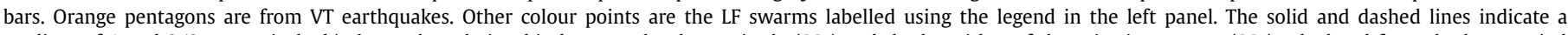

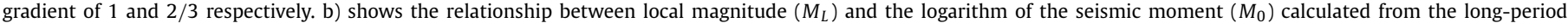
spectral level.

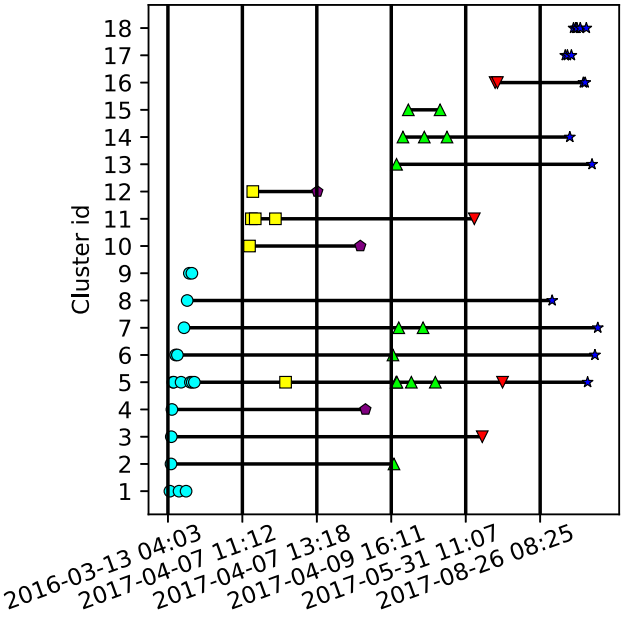

Fig. 8. a) shows the occurrence of low-frequency earthquakes in particular clusters. The six segments of the x-axis represent 30-minute-long periods starting at the time indicated below the respective segment. Earthquakes are plotted at their origin-time within their correct segment and according to their cluster id. Colours and symbols indicate the swarm each earthquake is located in according to the scheme in Figs. 3 and 4.

swarm are located across a wide region such that the waveforms are not similar, or that the earthquakes do not share common mechanisms.

\subsection{Stress drop}

We calculate the stress drops from all LF earthquakes and the 1200 VT earthquakes from Greenfield et al. (2019). Most (61\%) of the LF earthquakes have at least one stress-drop estimate from the stations which record each particular earthquake. We make only 58 (5\%) stress-drop estimates from the VT earthquakes. The low percentage is primarily because of the relatively low sampling rate (50 samples-per-second) and that stations were placed very close to anthropogenic noise sources (e.g. schools, houses, medical centres) which obscure the corner frequency. This results in greater errors in stress drop for VT events (Fig. 9) and because corner frequency scales with magnitude, only VT earthquakes with $M_{L}$ higher than 1.6 were analysed. The final stress-drop for each

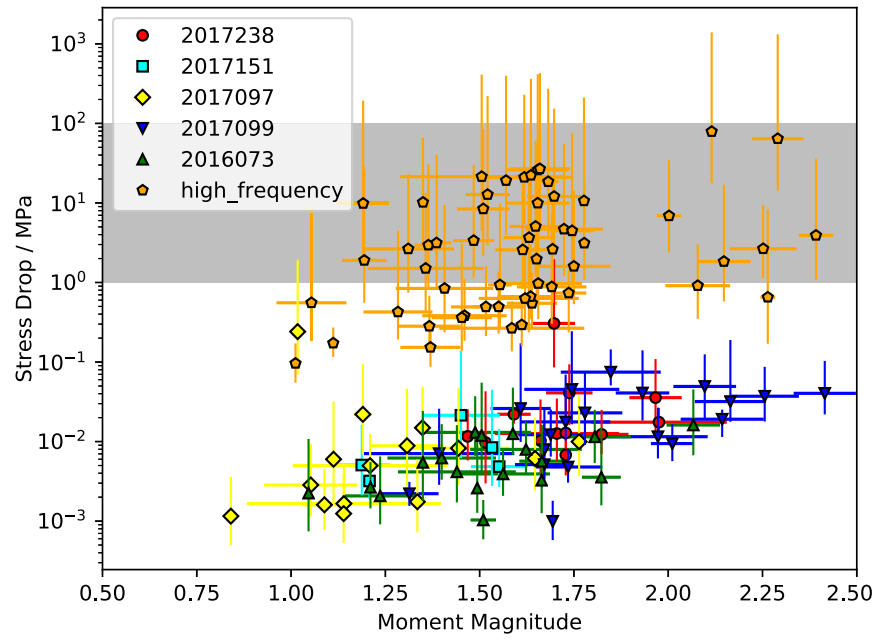

Fig. 9. Stress drop estimates from Tullu Moye seismicity plotted against moment magnitude. Results from VT earthquakes are plotted as orange pentagons with error bars. The remaining points indicate the results from LF swarms labelled as the legend. The grey background region indicates the global range of stress drop estimates (1-100 MPa).

earthquake is calculated using the mean and summarised in Supplementary Dataset 1.

A clear distinction is observed between the LF and VT earthquakes (Fig. 9). LF earthquakes consistently have stress-drops 1-2 orders of magnitude smaller than VT earthquakes. The stressdrop recorded for LF earthquakes also depends slightly on moment, while no such relationship is seen in the VT events (Fig. 9). Globally, stress-drops are observed to be between 1-100 MPa (Kanamori and Brodsky, 2004). Within error, most VT earthquakes fit in this range, indicating that our analysis produces sensible results and that the LF earthquakes are significantly lower in stress drop (Fig. 9).

\section{Discussion}

LF earthquakes are detected around numerous volcanoes around the world, although are most common during eruptive episodes (e.g., Iverson et al., 2006; Bell et al., 2017). Earthquakes during these swarms are highly similar to each other and contain long 

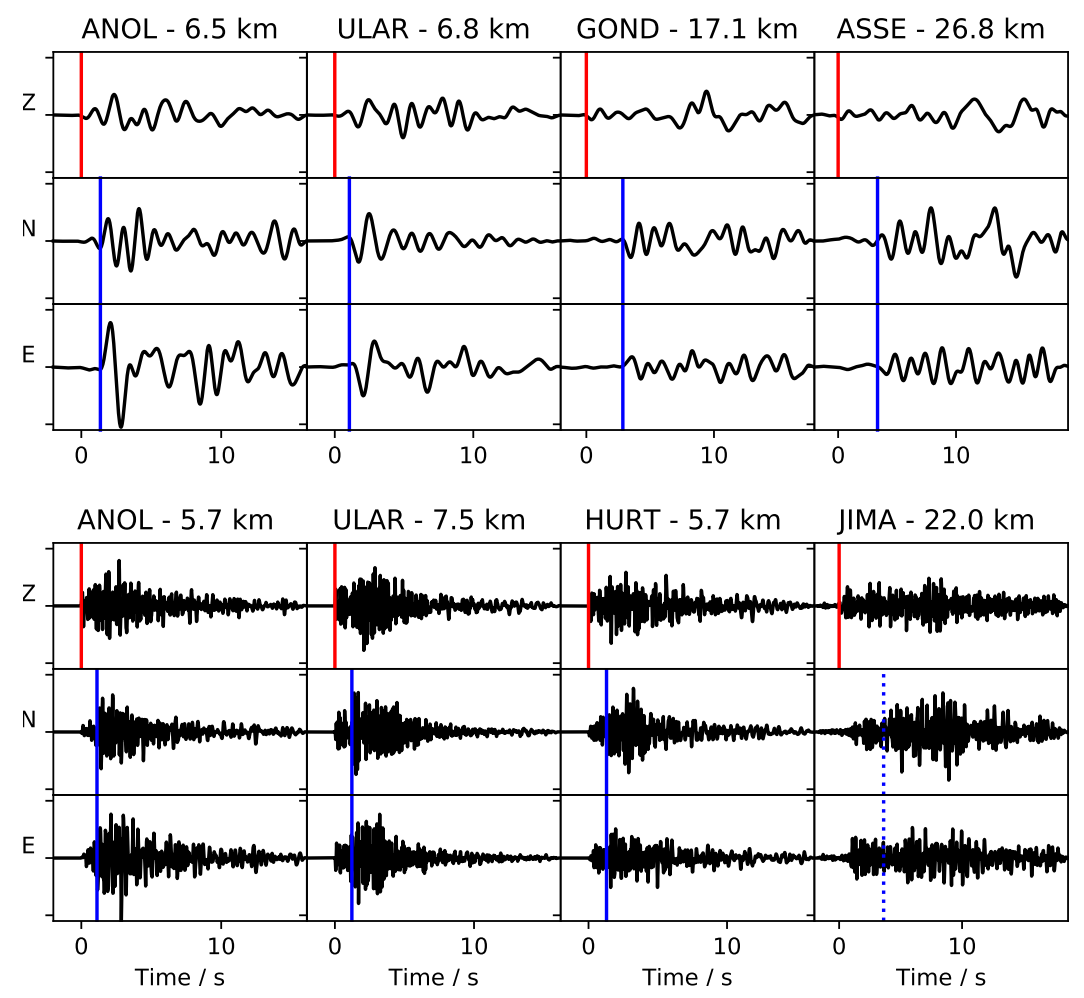

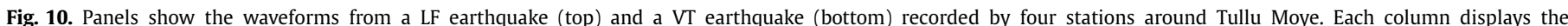

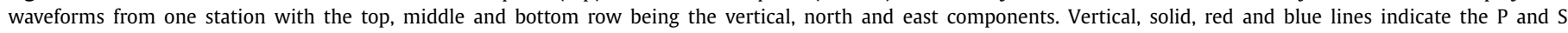
arrival time picks respectively. Dotted lines indicate theoretical arrival time picks. The epicentral distance is indicated next to the station name.

resonating codas which can be the result of tube waves resonating within a magma conduit (Neuberg et al., 2006) or resonating cracks close to the surface (Chouet, 1988; Kumagai et al., 2005), for example. Importantly, the depth of these types of LF earthquakes are all very shallow $(<1 \mathrm{~km})$. In contrast, the seismicity beneath TM does not contain a unique repeating event, although some similar earthquakes are present within many of the swarms. The earthquakes are fairly deep (approximately 3-7 km below the surface) and there is no evidence for extended codas (Fig. 10). As such, it is unlikely that the models used to explain the features of shallow LF events can be used to explain the LF earthquakes observed beneath TM.

\subsection{Waveform properties}

The stress-drop analysis shows that despite the LF energy, the spectra can be well-modelled using the Brune (1970) framework with a clear identification of $f_{c}$. It is the value of $f_{c}$ that results in the low stress-drops calculated for the LF events. Within (2) there is a trade-off present between $f_{c}$ and the attenuation parameter, $Q$. Volcanic regions can have regions with very high attenuation (i.e. Zucca and Evans, 1992) especially near the surface (i.e. Jolly et al., 2012). High attenuation can mask $f_{c}$ causing the spectra to be well fitted with low $f_{c}$ and 'normal' attenuation parameters. We can discount a high-attenuation path or station effect, as similar $f_{c}$ are recorded on different stations at different azimuths. The earthquakes being located in an unmodelled broad high attenuation region also seems unlikely as VT and LF earthquakes are located less than $2 \mathrm{~km}$ from each other (Fig. 4) and we calculate $Q$ in the region around our earthquakes to be approximately 30 (Supplementary Fig. 3). This is similar to that observed in hydrothermal areas around many volcanoes (e.g. Clawson et al., 1989) and is characteristic of relatively high attenuation. Distinguishing between an extremely high attenuation source region and low corner frequencies is trickier. Simple modelling using the framework outlined in Section 3.2 show that to produce the low $f_{c}$ observed, $Q$ of between 0.1 and 1 is required over a distance of $280 \mathrm{~m}$ (travel time of $0.1 \mathrm{~s}$ at $2.8 \mathrm{~km} \mathrm{~s}^{-1}$ ). Such low values of $Q$ are lower than that observed around the melt lense beneath the East Pacific Rise (Wilcock et al., 1992) and lower than observed at temperatures greater than the solidus temperature of gabbronorite (Fontaine et al., 2005). While this does not prove that such low $Q$ is possible, it does suggest that regions which are so attenuating are probably not capable of supporting brittle failure. We therefore can conclude that attenuation can, at most, have only a minor effect on our stress drop results.

There is an implicit trade-off in the stress-drop analysis between $\Delta \sigma$ and $V_{R}$ (as a fraction of $V_{S}$ ) of the earthquake because the rupture velocity affects the value of the parameter $k$ in (4). Low $V_{R}$ reduces $k$ resulting in a lower corner frequency required for the same stress-drop. Reducing $V_{R}$ to $0.5 V_{s}$ (Kaneko and Shearer, 2014) cannot account for the low stress-drops observed, but, significantly lower $V_{R}$ (i.e. $1 \%$ of $V_{S}$ ) probably could account for the low observed stress-drops.

In such a model the stress-drops would be between 1-100 MPa (i.e., within global ranges) but low $V_{R}$ would result in low frequencies being generated. Low $V_{R}$ are also responsible for generating the LF earthquakes analysed by Bean et al. (2014) on Etna, Sicily. However, in our case, the model is unlikely to be slow rupture of near-surface unconsolidated sediments because of the greater depth of the TM earthquakes. Slow rupture earthquakes are common in subductions settings where large magnitude slow ruptures, LF tremor and LF earthquakes all occur in the accretionary prism (Peng and Gomberg, 2010). The slow rupture velocities in these settings are primarily driven by high pore fluid pressures and/or high temperatures (Peng and Gomberg, 2010). It is these models which we appeal to in order to explain the occurrence of LF earthquakes beneath TM. 


\subsection{Earthquake locations}

LF seismicity is located in two regions to the north-west and east of the VT seismicity beneath TM. Relative earthquake locations (Fig. 4) clearly show that each swarm locates to one of the two earthquake locations. It may then be expected that earthquake families (as defined using earthquake similarity, Fig. 8) would only contain events from swarms which locate to one of the earthquake clusters. However, Fig. 8 shows that this is not the case. Instead certain families (i.e. family 5, Fig. 8) contain events from 5 out of the 6 identified swarms. Family definitions are very dependent on the windows used to calculate the cross-correlation coefficient and the minimum correlation value used to define a family. We varied these parameters but could not separate earthquake swarms or clusters into distinct earthquake families. Instead, the high degree of similarity between events must be due to similar focal mechanisms within each cluster and the low frequency content. As a rule of thumb, earthquakes within a $1 / 4$ wavelength of each other may be expected to share quite similar waveforms (Waldhauser and Ellsworth, 2000). For these LF earthquakes beneath TM, this distance is approximately $0.9-3.5 \mathrm{~km}$ (using a shear wave velocity of $2.8 \mathrm{~km} \mathrm{~s}^{-1}$ and frequencies between 0.2 and $0.8 \mathrm{~Hz}$ ). The two clusters are located approximately $3 \mathrm{~km}$ from one another, suggesting this is probably the cause of the similar waveforms. The high number of earthquake families present within a single swarm despite their similar locations suggest that earthquake mechanisms within a swarm are highly diverse. This is probably due to a wide range of seismogenic structures available for brittle failure.

\subsection{Magma movement as a possible model}

Volcanic regions are characterised by high temperatures and pore fluid pressures. These, in combination with large seismic velocity contrasts formed during the movement of magma through the crust produce a variety of possibilities for the formation of LF events. Such models are often used to explain the deeper (depth $>5 \mathrm{~km}$ ) LF earthquakes observed around many volcanoes (e.g., Greenfield and White, 2015; Hensch et al., 2019; Shapiro et al., 2017). However, the movement of melt is an unattractive option for explaining the LF events beneath TM. Firstly, given the relatively shallow focus of the seismicity we might expect any magma intrusion to be accompanied with surface deformation. Deformation is observed around TM but is spatially centred $15 \mathrm{~km}$ west of the TM crater (Biggs et al., 2011). Secondly, while magma intrusion can be accompanied by small numbers of LF earthquakes, it is almost always accompanied with large numbers of migrating VT earthquakes (e.g., Sigmundsson et al., 2015). VT earthquakes are detected close to TM, but no migration is observed over the 1.5-year network deployment, and VT events and LF events are spatially distinct from one another suggesting they have different mechanisms.

\subsection{LF earthquake model}

Given the lack of evidence for magma movement beneath TM, we propose that the LF seismicity is induced by the movement of volatiles through the crust. The volatiles are likely to be predominantly water, which at these temperatures and pressures is probably supercritical, although $\mathrm{CO}_{2}$ could also be present. The movement of these fluids would cause high pore fluid pressures which encourages brittle failure at lower stresses. The high pore fluid pressures would also cause the LF nature of the seismicity in a similar mechanism as beneath subduction zones (Peng and Gomberg, 2010).

The seismicity is located in two clusters (Fig. 4), and each swarm locates to one of the two locations. This indicates that, currently, there are two regions beneath TM that are capable of producing detectable LF seismicity. Therefore, there must either be two sources of high-temperatures and fluids, or one location and two preferred flow directions. A single source model seems unlikely, because there is no suggestion of any strong NW-SE structures in this area (Greenfield et al., 2019) and any radially expanding fluid front would probably activate both clusters during a single swarm. Instead, we propose that there are two sources of the specific conditions in which LF earthquakes arise beneath TM. In these seismogenic regions, a diversity of fault orientations causes failure to occur in multiple different mechanisms, so causing the diversity of earthquake families we observe.

The fluids inducing the seismicity could be sourced from magma bodies beneath TM. Magmas in the MER can have very high volatile contents due to extensive fractionation in the crust (Iddon et al., 2018; Hutchison et al., 2018). Indeed, the most recent eruptions from TM are highly fractionated rhyolites, suggesting that a shallow magma chamber beneath TM could be rhyolitic. Recent conductivity measurements (Samrock et al., 2018) show a single high-conductivity region, consistent with a high-fluid, rhyolitic magma, present beneath TM. The location and depth of this body are in line with the hypocentral locations of the LF earthquakes, indicating that this magma body is probably the source for the high-temperatures and fluids driving LF seismicity. The conductivity observations suggest a single magma body, but our earthquake locations suggest either: two distinct places where fluids can be released into the surrounding crust, or, heterogeneity in fluid content and temperature within the body. The depth of this magma body is within the range of depths suggested for a heavily intruded, but seismogenic, region of the crust beneath Aluto (Wilks et al., 2017) and slightly shallower than the depth of magma intrusion beneath Corbetti (Lloyd et al., 2018; Gíslason et al., 2015).

\section{Conclusions}

We have detected and located 6 swarms of low-frequency seismicity during a 1.5-year period close to Tullu Moye volcano in the Main Ethiopian Rift. Detailed analysis of the seismicity reveals that it is sourced from two locations at a depth of $1-5 \mathrm{~km}$ bsl (3-7 $\mathrm{km}$ below surface). We propose the seismicity is triggered by the release of volatiles (probably $\mathrm{H}_{2} \mathrm{O} / \mathrm{CO}_{2}$ mixtures) from a shallow magma body centred beneath TM. The fluid source is likely to be a cooling magma body related to the most recent eruptive of Tullu Moye activity 100-200 years ago. The two clusters are locations where the pore fluid pressures are increased to high enough levels to induce brittle failure but with low rupture velocities. This causes the low-frequency content of the earthquakes. The results we present suggest a minimum depth for a potential magmatic body beneath Tullu Moye ( $\sim 4 \mathrm{~km}$ below the surface) and that it must have very high volatile content. This must mean that it is a silica-rich magma body that has undergone significant fractionation. Volatiles are then released from this body episodically.

\section{Acknowledgements}

This research is supported by the NERC through grant NE/ L013932/1. Instruments were loaned by SEIS-UK. The facilities of SEIS-UK supported by the Natural Environment Research Council under agreement R8/H10/64. We thank all those involved in field-work; especially Ethioder Logistics and the Institute of Geophysics, Space Science and Astronomy (IGSSA), Addis Ababa University without whom the project would not have succeeded. J. Ritter and two anonymous reviewers greatly improved the quality of manuscript. Seismic data is stored at SEIS-UK and although cur- 
rently embargoed, will be available, open-access, on IRIS (https:// www.iris.edu/hq/) after October 2020. Datasets generated from this study, such as earthquake hypocenters, can be downloaded from the Supplementary Information. Generic Mapping Tools (GMT) (Wessel et al., 2013) was used to make some of the figures and Obspy (Beyreuther et al., 2010) was used extensively for data analysis.

\section{Appendix A. Supplementary material}

Supplementary material related to this article can be found online at https://doi.org/10.1016/j.epsl.2019.115782.

\section{References}

Abercrombie, R.E., 1995. Earthquake source scaling relationships from -1 to 5 ML, using seismograms recorded at $2.5 \mathrm{~km}$ depth. J. Geophys. Res. 100, 24015-24036.

Bean, C.J., Barros, L.D., Lokmer, I., Métaxian, J.-P., O’Brien, G., Murphy, S., 2014. Longperiod seismicity on the shallow volcanic edifice formed from slow-rupture earthquakes. Nat. Geosci. 7, 71-75. https://doi.org/10.1038/ngeo2027.

Bell, A.F., Hernandez, S., Gaunt, H.E., Mothes, P., Ruiz, M., Sierra, D., Aguaiza, A., 2017. The rise and fall of periodic 'drumbeat' seismicity at Tungurahua volcano, Ecuador. Earth Planet. Sci. Lett. 475, 58-70. https://doi.org/10.1016/j.epsl.2017. 07.030.

Beyreuther, M., Barsch, R., Krischer, L., Megies, T., Behr, Y., Wassermann, J., 2010. ObsPy: a Python toolbox for seismology. Seismol. Res. Lett. 81, 530-533. https:// doi.org/10.1785/gssrl.81.3.530.

Biggs, J., Bastow, I.D., Keir, D., Lewi, E., 2011. Pulses of deformation reveal frequently recurring shallow magmatic activity beneath the Main Ethiopian Rift. Geochem. Geophys. Geosyst. 12, 1-11. https://doi.org/10.1029/2011GC003662.

Boatwright, J., 1980. A spectral theory for circular seismic sources: simple estimates of source dimension, dynamic stress drop and radiated energy. Bull. Seismol. Soc. Am. 70, 1-27.

Bonini, M., Corti, G., Innocenti, F., Manetti, P., Mazzarini, F., Abebe, T., Pecskay, Z., 2005. Evolution of the Main Ethiopian Rift in the frame of Afar and Kenya rifts propagation. Tectonics 24 (1). https://doi.org/10.1029/2004TC001680.

Brune, J.N., 1970. Tectonic stress and the spectra of seismic shear waves from earthquakes. J. Geophys. Res. 75 (26), 4997-5009. https://doi.org/10.1029/ JB075i026p04997.

Butcher, A., Luckett, R., Verdon, P., Kendall, J.-M., Baptie, B., Wookey, J., 2017. Local magnitude discrepancies for near-event receivers: implications for the U.K. traffic-light scheme. Bull. Seismol. Soc. Am. 107 (2), 532-541. https://doi.org/10. 1785/0120160225.

Buurman, H., West, M.E., 2010. Seismic precursors to volcanic explosions during the 2006 eruption of Augustine Volcano. In: Power, J.A., Coombs, M.L., Freymueller, J.T. (Eds.), The 2006 Eruption of Augustine Volcano. In: U.S. Geological Survey Professional Paper, vol. 1769, pp. 41-57.

Chouet, B., 1988. Resonance of a fluid-filled crack: radiation properties and implications for the source of long-period events and harmonic tremor. J. Geophys. Res. 93, 4375-4400.

Chouet, B.A., Matoza, R.S., 2013. A multi-decadal view of seismic methods for detecting precursors of magma movement and eruption. J. Volcanol. Geotherm. Res. 252, 108-175

Clawson, S.R., Smith, R.B., Benz, H.M., 1989. P wave attenuation of the Yellowstone Caldera from three-dimensional inversion of spectra decay using explosion source seismic data. J. Geophys. Res. 96 (B6), 7205-7222. https://doi.org/ 10.1029/JB094iB06p07205. doi.

Corti, G., Philippon, M., Sani, F., Keir, D., Kidane, T., 2013. Re-orientation of the extension direction and pure extensional faulting at oblique rift margins: comparison between the Main Ethiopian Rift and laboratory experiments. Terra Nova 25 (5), 396-404. https://doi.org/10.1111/ter.12049.

De Meersman, K., Kendall, J.-M., van der Baan, M., 2009. The 1998 Valhall microseismic data set: an integrated study of relocated sources, seismic multiplets, and S-wave splitting. Geophysics 74 (5), B183-B195. https://doi.org/10.1190/1. 3205028.

Ebinger, C.J., Casey, M., 2001. Continental breakup in magmatic provinces: an Ethiopian example. Geology 29 (6), 527-530. https://doi.org/10.1130/00917613(2001)029\%3C0527:CBIMPA\%3E2.0.CO;2.

Edwards, B., Allmann, B., Fäh, D., Clinton, J., 2010. Automatic computation of moment magnitudes for small earthquakes and the scaling of local to moment magnitude. Geophys. J. Int. 183, 407-420. https://doi.org/10.1111/j.1365-246X. 2010.04743.x.

Eshelby, J.D., 1957. The determination of the elastic field of an ellipsoidal inclusion and related problems. Proc. R. Soc. Lond. A 241, 376-396.

Font, Y., Kao, H., Lallemand, S., Liu, C.-S., Chiao, L.-Y., 2004. Hypocentral determination offshore Eastern Taiwan using the maximum intersection method. Geophys. J. Int. 158, 655-675. https://doi.org/10.1111/j.1365-246X.2004.02317.x.
Fontaine, F.R., Ildefonse, B., Bagdassarov, N.S., 2005. Temperature dependence of shear wave attenuation in partially molten gabbronorite at seismic frequencies. Geophys. J. Int. 163, 1025-1038. https://doi.org/10.1111/j.1365-246X.2005. 02767.xx.

Fontijn, K., McNamara, K., Tadesse, A.Z., Pyle, D.M., Dessalegn, F., Hutchinson, W. Mather, T.A., Yirgu, G., 2018. Contrasting styles of post-caldera volcanism along the Main Ethiopian Rift: implications for contemporary volcanic hazards. J. Volcanol. Geotherm. Res. 356, 90-113. https://doi.org/10.1016/j.jvolgeores.2018.02. 001.

Frank, W.B., Shapiro, N.M., Gusev, A.A., 2018. Progressive reactivation of the volcanic plumbing system beneath Tolbachik volcano (Kamchatka, Russia) revealed by long-period seismicity. Earth Planet. Sci. Lett. 493, 47-56. https://doi.org/10. 1016/j.epsl.2018.04.018. doi.

Gíslason, G., Eysteinsson, H., Björnsson, G., Harardóttir, V. 2015. Results of surface exploration in the Corbetti Geothermal Area, Ethiopia. Paper presented at World Geothermal Congress, Melbourne, Australia, 19-25 April 2015.

Global Volcanism Program, 2013. Tullu Moje (221250) in Volcanoes of the World, v. 4.7.7. Venzke, E. (Ed.). Smithsonian Institution. https://volcano.si.edu/volcano. cfm?vn=221250. Downloaded 24 Apr 2019.

Green, D.N., Neuberg, J., 2006. Waveform classification of volcanic low-frequency earthquake swarms and its implication at Soufrière Hills Volcano, Montserrat. J. Volcanol. Geotherm. Res. 153, 51-63. https://doi.org/10.1016/j.jvolgeores.2005. 08.003.

Greenfield, T., Keir, D., Kendall, J-M., Ayele, A., 2019. Seismicity of the Bora-Tullu Moye volcanic field, 2016-2017. Geochem. Geophys. Geosyst. 20, 548-570. https://doi.org/10.1029/2018GC007648.

Greenfield, T., White, R.S., 2015. Building Icelandic igneous crust by repeated melt injections. J. Geophys. Res. 120, 1-14. https://doi.org/10.1002/2015JB012009.

Gouin, P., 1979. Earthquake History of Ethiopia and the Horn of Africa, 1st ed. International Development Research Centre, Ottawa, Ontario, Canada.

Hensch, M., Dahm, T., Ritter, R., Heimann, S., Schmidt, B., Stange, S., Lehmann, K. 2019. Deep low-frequency earthquakes reveal ongoing magmatic recharge beneath Laacher See Volcano (Eifel, Germany). Geophys. J. Int. 216 (3), 2025-2036. httpds://doi.org/10.1093/gji/ggy532.

Hutchison, W., Mather, Tamsin A., Pyle, David, Boyce, Adrian, Gleeson, Matthew, Yirgu, Gezahegn, Blundy, Jon D., Ferguson, David J., Vye-Brown, Charlotte, Millar Ian, Sims, Kenneth, Finch, Adrian, 2018. The evolution of magma during continental rifting: new constraints from the isotopic and trace element signatures of silicic magmas from Ethiopian volcanoes. Earth Planet. Sci. Lett. 489, 203-218. https://doi.org/10.1016/j.epsl.2018.02.027.

Iddon, F., Jackson, C., Hutchinson, W., Fontijn, K., Pyle, D., Mather, T.A., Yirgu, G., Edmonds, M., 2018. Mixing and crystal scavenging in the Main Ethiopian Rift revealed by trace element systematics in feldspars and glasses. Geochem. Geophys. Geosyst. 20. https://doi.org/10.1029/2018GC007836.

Iverson, R.M., Dzurisin, D., Gardner, C.A., Gerlach, T.M., LaHusen, R.G., Lisowski, M. Major, J.J., Malone, S.D., Messerich, J.A., Moran, S.C., Pallister, J.S., Qamar, A.I., Schilling, S.P., Vallance, J.W., 2006. Dynamics of seismogenic volcanic extrusion at Mount St Helens in 2004-2005. Nature 444, 439-443. https://doi.org 10.1038 /nature05322.

Jolly, A.D., Chardot, L., Neuberg, J., Fournier, N., Scott, B.J., Sherburn, S., 2012. High impact mass drops from helicopter: a new active seismic source method applied in an active volcanic setting. Geophys. Res. Lett. 39, L12306. https://doi.org/10. 1029/2012GL051880.

Kanamori, H., 1977. The energy release in great earthquakes. J. Geophys. Res. 82, 2981-2987.

Kanamori, H., Brodsky, E., 2004. The physics of earthquakes. Rep. Prog. Phys. 67, 1429-1496. https://doi.org/10.1088/0034-4885/67/8/R03.

Kaneko, Y., Shearer, P.M., 2014. Seismic source spectra and estimated stress drop derived from cohesive-zone models of circular subshear rupture. Geophys. J. Int. 197 (2), 1002-1015. https://doi.org/10.1093/gji/ggu030.

Keir, D., Stuart, G.W., Jackson, A., Ayele, A., 2006. Local earthquake magnitude scale and seismicity rate for the Ethiopian rift. Bull. Seismol. Soc. Am. 96, 2221-2230. https://doi.org/10.1785/0120060051.

Kumagai, H., Chouet, B.A., Dawson, P.B., 2005. Source processes of a long-period event at Kilauea volcano, Hawaii. Geophys. J. Int. 161, 243-254.

Lloyd, R., Biggs, J., Birhanu, Y., Wilks, M., Gottsmann, J., Kendall, J.-M., et al., 2018. Sustained uplift at a continental rift caldera. J. Geophys. Res., Solid Earth 123 5209-5226. https://doi.org/10.1029/2018JB015711.

Lomax, A., Michelini, A., Curtis, A., 2009. Earthquake location, direct, global-search methods. In: Encyclopedia of Complexity and System Science, Part 5. Springer, New York, pp. 2449-2473.

Madriaga, R., 1976. Dynamics of an expanding circular fault. Bull. Seismol. Soc Am. 66, 639-666.

McNutt, S.R., 2005. Volcanic Seismology. Annu. Rev. Earth Planet. Sci. 33, 461-491. https://doi.org/10.1146/annurev.earth.33.092203.122459.

Mohr, P.A., 1968. Transcurrent faulting in the Ethiopian Rift System. Nature 218 938-941.

Neuberg, J.W., Tuffen, H., Collier, L., Green, D., Powell, T., Dingwell, D., 2006. The trigger mechanism of low-frequency earthquakes on Montserrat. J. Volcanol Geotherm. Res. 153 (1), 37-50. https://doi.org/10.1016/j.jvolgeores.2005.08.008. 
Ominato, T., Chouet, B., Dawson, P., Kedar, S., 1998. Waveform inversion of very long period impulsive signals associated with magmatic injection beneath Kilauea Volcano Hawaii. J. Geophys. Res. 103 (B10), 23839-23862. https://doi.org/ 10.1029/98JB01122. doi.

Park, J., Lindberg, C.R., Vernon, F.L., 1987. Multitaper spectral analysis of highfrequency seismograms. J. Geophys. Res. 92 (B12), 12675-12684. https://doi.org/ 10.1029/JB092iB12p12675.

Peng, Z., Gomberg, J., 2010. An integrated perspective of the continuum between earthquakes and slow-slip phenomena. Nat. Geosci. 3, 599-607. https://doi.org/ 10.1038/ngeo940.

Power, J.A., Stihler, S.D., White, R.A., Moran, S.C., 2004. Observations of deep long period (DLP) seismic events beneath Aleutian arc volcanoes (1989-2002). J. Volcanol. Geotherm. Res. 138, 243-266. https://doi.org/10.1016/j.jvolgeores.2004.07. 005.

Prieto, G.A., Parker, R.L., Vernon III, F.L., 2009. A Fortran 90 library for multitaper spectrum analysis. Comput. Geosci. 35 (8), 1701-1710. https://doi.org/10.1016/ j.cageo.2008.06.007.

Roman, D.C., Cashman, K.V., 2006. The origin of volcano-tectonic earthquake swarms. Geology 34 (6), 457-460. https://doi.org/10.1130/G22269.1.

Samrock, F., Grayver, A.V., Eysteinsson, H., Saar, M., 2018. Magnetotelluric image of transcrustal magmatic system beneath the Tulu Moye geothermal prospect in the Ethiopian Rift. Geophys. Res. Lett. 45, 12,847-12,855. https://doi.org/10. 1029/2018GL080333.

Shapiro, N.M., Droznin, D.V., Droznina, S.Ya., Senyukov, S.L., Gusev, A.A., Gordeev, E.I., 2017. Deep and shallow long-period volcanic seismicity linked by fluid-pressure transfer. Nat. Geosci. 10, 442-445. https://doi.org/10.1038/ngeo2952. doi.

Shearer, P.M., Prieto, G., Hauksson, E., 2006. Comprehensive analysis of earthquake source spectra in southern California. J. Geophys. Res. 111, B6. https://doi.org/ 10.1029/2005JB003979.
Sigmundsson, et al., 2015. Segmented lateral dyke growth in a rifting event at Bárðarbunga volcanic system, Iceland. Nature 517, 181-195. https://doi.org/10. 1038/nature14111.

Tuffen, H., Smith, R., Sammonds, P.R., 2008. Evidence for seismogenic fracture of silicic magma. Nature 453, 511-514. https://doi.org/10.1038/nature06989.

Waldhauser, F., Ellsworth, W.L., 2000. A double-difference earthquake location algorithm: method and application to the northern Hayward fault. Bull. Seismol. Soc. Am. 90, 1353-1368.

Wessel, P., Smith, W.H.F., Scharroo, R., Luis, J., Wobbe, F., 2013. Generic mapping tools: improved version released. Eos Trans. Am. Geophys. Union 94, 409-410. https://doi.org/10.1002/2013E0450001.

Wilcock, W.S.D., Solomon, S.C., Purdy, G.M., Toomey, D.R., 1992. The seismic attenuation structure of a fast-spreading mid-ocean ridge. Science 258 (5087), 1470-1474. https://doi.org/10.1126/science.258.5087.1470.

Wilks, M.T., Kendall, J.M., Nowacki, A.J., Biggs, J., Wookey, J., Birhanu, Y., Ayele, A., Bedada, T., 2017. Seismicity associated with magmatism, faulting and hydrothermal circulation at Aluto Volcano, Main Ethiopian Rift. J. Volcanol. Geotherm. Res. 340, 52-67. https://doi.org/10.1016/j.jvolgeores.2017.04.003. doi.

Woldegabriel, G., Aronson, J.L., Walter, R.C., 1990. Geology, geochronology, and rift basin development in the central sector of the Main Ethiopia Rift. Geol. Soc. Am. Bull. 102 (4), 439-458. https://doi.org/10.1130/0016-7606(1990)102\%3C0439: GGARBD\%3E2.3.CO;2.

Wolfenden, E., Ebinger, C., Yirgu, G., Deino, A., Ayalew, D., 2004. Evolution of the northern Main Ethiopian rift: birth of a triple junction. Earth Planet. Sci. Lett. 224 (1-2), 213-228. https://doi.org/10.1016/j.epsl.2004.04.022.

Zucca, J.J., Evans, J.R., 1992. Active high-resolution compressional wave attenuation tomography at Newberry Volcano, Central Cascade Range. J. Geophys. Res. 97 (B7), 11047-11055. https://doi.org/10.1029/92JB00492. doi. 